\title{
Patient Characteristics, Health Care Resource Utilization, and Costs Associated with Treatment-Regimen Failure with Biologics in the Treatment of Psoriasis
}

\author{
Shonda A. Foster, MS, PharmD; Baojin Zhu, PhD; Jiaying Guo, MS; \\ Enkeleida Nikai, MSc, EMM\&A; Clement Ojeh, PhD; William Malatestinic, PharmD, MBA; \\ Orin Goldblum, MD; Lori J. Kornberg, PhD; and Jashin J. Wu, MD, FAAD
}

\begin{abstract}
BACKGROUND: Psoriasis is a chronic, incurable, and immune-mediated skin disorder that is characterized by erythematous scaly papules and plaques. Understanding of psoriasis at the molecular level has led to the development of biologic agents that target disease-specific inflammatory mediators in psoriatic lesions. Biologic agents have become important components of the psoriasis armamentarium, but some patients become refractory to these agents over time or fail to respond to subsequent biologics.
\end{abstract}

OBJECTIVES: To (a) evaluate demographic and clinical characteristics of psoriasis patients who have treatment patterns suggestive of failure to a newly initiated biologic agent (treatment-regimen failures) compared with those who do not (non-treatment-regimen failures) and (b) to assess health care-related resource utilization and costs in non-treatment-regimen failures and treatment-regimen failures.

METHODS: In this retrospective observational cohort study, patients were selected from the MarketScan claims database of commercially insured individuals and individuals with Medicare supplemental insurance. The index event was a newly initiated biologic agent for the treatment of psoriasis (etanercept, adalimumab, ustekinumab, or infliximab) between January 2010 and December 2011. The analysis included psoriasis patients aged $\geq 18$ years with $\geq 1$ prescription claim for a biologic and continuous enrollment 12 months pre- and post-index date. Patients with claims for a biologic in the pre-index period were excluded. Patients were divided into treatment-regimen-failure and non-treatment-regimen-failure groups based on their treatment patterns post-index date. The treatment-regimenfailure group included patients who switched to another biologic, discontinued the biologic without restarting, increased the dose of the biologic, or augmented treatment with a nontopical psoriasis medication during the post-index period. Between-group patient characteristics and medication use were compared using analysis of variance for continuous variables and chi-square tests for categorical variables without adjustment. Cost differences were compared using the propensity score-adjusted bin bootstrapping method.

RESULTS: Overall, 2,146 patients met the enrollment criteria. The mean age was 45.1 years. Of these patients, $41.5 \%$ were considered treatmentregimen failures. Among treatment-regimen failures, $53 \%$ were females, and among non-treatment-regimen failures, $61 \%$ were male. Patients who experienced treatment-regimen failure had higher incidences of comorbid cerebrovascular disease, hypertension, chronic pulmonary disease, depression, and anxiety in the pre-index period and were more likely to use concomitant topicals ( $67.0 \%$ vs. $58.4 \% ; P<0.001)$, methotrexate $(20.2 \%$ vs. $7.3 \% ; P<0.001)$, and cyclosporine $(3.1 \%$ vs. $1.0 \% ; P<0.001)$ in the post-index period. Mean total all-cause health care costs were higher in patients with treatment-regimen failure versus non-treatment-regimen fail- ure during the pre-index period ( $\$ 8,024$ vs. $\$ 6,637 ; P=0.002)$, but patients with non-treatment-regimen failure had higher all-cause costs $(\$ 30,759$ vs. $\$ 28,012 ; P=0.002)$ and psoriasis-related costs $(\$ 25,286$ vs. $\$ 19,625$; $P<0.001)$ during the post-index period.

CONCLUSIONS: The results of the current study demonstrated that psoriasis patients with treatment patterns suggestive of treatment-regimen failure on an index biologic had different characteristics and incurred higher all-cause health care costs than did patients without treatment-regimen failure during the pre-index period.

J Manag Care Spec Pharm. 2016;22(4):396-405

Copyright $\odot 2016$, Academy of Managed Care Pharmacy. All rights reserved.

\section{What is already known about this subject}

Plaque psoriasis is a chronic incurable skin disorder with signs and symptoms (visible red and scaly lesions, pain, and pruritus) that can affect health-related quality of life and productivity.

Understanding of psoriasis at the molecular level has led to the development of biologic agents that target inflammatory mediators in psoriatic lesions.

Some patients can be biologic contraindicated, fail to respond to first-line biologic therapy, or become refractory to biologic agents over time.

\section{What this study adds}

A higher proportion of those identified as treatment-regimen failures were female and had a higher incidence of some comorbidities in the pre-index period compared with non-treatmentregimen failures.

Patients who experienced treatment-regimen failure with biologic therapy had higher use of concomitant medications, including topicals, compared with those who did not experience treatmentregimen failure, suggesting that current biologic therapy may be inadequate in a significant number of patients.

Mean total health care-related costs and psoriasis-related health care costs were higher in non-treatment-regimen failures than treatment-regimen failures during the post-index period; however, non-treatment-regimen failures had lower all-cause outpatient costs in both the pre- and post-index periods compared with treatment-regimen failures. 
$\mathrm{P}$ laque psoriasis (psoriasis vulgaris or chronic plaque psoriasis) is a chronic, immune-mediated skin disorder characterized by erythematous scaly papules and plaques. It is a complex condition with both physical (visible red, scaly lesions; pain; pruritus) and psychosocial consequences that affect overall quality of life and productivity. ${ }^{1-3}$ Associated comorbidities, such as diabetes, cardiovascular disease, metabolic syndrome, autoimmune diseases, and depression $^{3-9}$ complicate the medical management of these patients. Additionally, as many as $20 \%$ to $30 \%$ of psoriasis patients have psoriatic arthritis (joint involvement), ${ }^{10}$ which further adds to the burden of these patients.

Psoriasis is incurable, so emphasis is on disease management. Treatment goals include reduction of the size, thickness, and extent of the lesions and erythema and improvement in health-related quality of life. ${ }^{11}$ Depending on disease severity, psoriasis is treated with (alone or in combination therapy) topical agents, phototherapy, oral systemic agents (e.g., methotrexate, cyclosporine, acitretin, apremilast), and biologics (e.g., etanercept, adalimumab, infliximab, ustekinumab). ${ }^{11-14}$ Understanding of psoriasis at the molecular level has led to the development of biologic agents that inhibit T-cell function and block tumor necrosis factor (TNF)- $\alpha$, interleukin (IL)-12/IL-23, and IL-17 activities. ${ }^{10,12,15,16}$

Biologic agents have become important components of the psoriasis armamentarium, but individuals can become refractory to some biologic agents over time, fail to respond to firstline treatment, or have treatment contraindications. ${ }^{12}$ In 2005 , Feldman et al. reported treatment-regimen failure rates and direct medical costs associated with psoriasis therapy using claims data, but their study did not include biologic agents. ${ }^{17}$ More recent studies have evaluated the reasons for treatment changes in biologic-treated patients ${ }^{18}$ and treatment patterns/ costs among biologic-treated patients ${ }^{19}$ using chart reviews and claims data, respectively, but these studies did not compare patients who responded to first biologic therapy with those who did not.

Failure to respond to therapy has both medical and economic consequences. An understanding of the characteristics of patients who fail to respond to first biologic therapy and the impact of failure to respond to first therapy on health care utilization and costs may provide important insights to clinicians and payers. We hypothesized that patients who experience treatment-regimen failure would have greater resource utilization and costs compared with non-treatment-regimen failures. Thus, the objectives of this retrospective, observational study were to (a) evaluate demographic and clinical characteristics of patients who had treatment patterns suggestive of failure to the first received biologic therapy (treatment-regimen failures) compared with those who did not (non-treatment-regimen failures) and (b) assess health care-related resource utilization and costs in treatment-regimen failures and non-treatment-regimen failures.

\section{Methods}

\section{Data Source and Patient Selection}

The study population was extracted from Truven Health Analytics' MarketScan Commercial Claims and Encounters Database and the Medicare Supplemental and Coordination of Benefits Database. This study enrolled patients newly initiating a biologic (etanercept, adalimumab, ustekinumab, or infliximab) with $\geq 1$ biologic prescription drug claim between January 1, 2010, and December 31, 2011. The biologic initiation date was the index date and patients had to have continuous enrollment (medical and pharmacy benefits) for 12 months pre-index and 12 months post-index date. Additionally, patients had to be $\geq 18$ years of age on the index date and had evidence of a psoriasis diagnosis (International Classification of Diseases, Ninth Revision, Clinical Modification [ICD-9-CM] code 696.1) during the 12-month pre-index period as defined by (a) $\geq 2$ outpatient visits, at least 30 days apart, with a psoriasis diagnosis and with at least 1 such diagnosis occurring in the 60 days prior to the index date or (b) $\geq 1$ inpatient admission with a psoriasis diagnosis.

Because claims data were used and the authors did not have access to clinical information related to treatment responses, treatment patterns were used to define treatment failure. ${ }^{17}$ Treatment-regimen failure was defined as individuals who switched to another biologic, discontinued their biologic without restarting the original biologic, or augmented treatment with a nontopical psoriasis medication. In addition, those who had a dose increase ( $\geq 30 \%$ ) above the recommended maintenance dose in the maintenance period were also included in the treatment-regimen-failure group. Non-treatment-regimen failure was defined as those not meeting the definition of treatment-regimen failure.

Patients with a medical claim for rheumatoid arthritis (ICD9-CM code 714.x [rheumatoid arthritis]); Crohn's disease (ICD-9-CM code 555.x [regional enteritis]); ulcerative colitis (ICD9-CM code 556.x [ulcerative (chronic) enterocolitis]); osteoarthritis (ICD-9-CM codes 715.0x [osteoarthrosis generalized], 715.1x [osteoarthrosis localized primary], 715.2x [osteoarthrosis localized secondary], 715.8x [osteoarthrosis involving or with more than 1 site but not specified as generalized], 715.9x [osteoarthrosis unspecified whether generalized or localized], 721.0 [cervical spondylosis without myelopathy], 721.1 [cervical spondylosis with myelopathy], 721.2 [thoracic spondylosis without myelopathy], 721.3 [lumbosacral spondylosis without myelopathy], 721.41 [spondylosis with myelopathy thoracic region], 721.42 [spondylosis with myelopathy lumbar region]); reactive arthritis (ICD-9-CM code 099.3 [Reiter's disease]); or ankylosing spondylitis (ICD-9-CM code 720.x [ankylosing spondylitis and other inflammatory spondylopathies]) during the pre-index period were excluded. Also excluded were patients with claims for a biologic (etanercept, adalimumab, 
ustekinumab, or infliximab) in the pre-index period. Patients with comorbid psoriatic arthritis (ICD-9-CM code 696.0 [psoriatic arthropathy]) were included.

This study was exempt from informed consent requirements, and institutional/ethical review board approval was not required because the patient records were deidentified.

The study period was January 1, 2009, to December 31, 2012. The index period was January 1, 2010, to December 31, 2011. The index date was defined as the first claim for a biologic with no claims for biologics in the pre-index period.

\section{Outcomes Measures}

The recommended maintenance doses were defined by the respective package inserts. ${ }^{20-23} \mathrm{~A}$ dose increase was defined as having a mean observed average daily dose $\geq 30 \%$ larger than the recommended U.S. Food and Drug Administration-approved maintenance dose (during the maintenance period). ${ }^{24,25}$

Switching was defined as a claim for a different biologic at any time during the post-index period after the index medication was discontinued. Discontinuation was defined as a gap of at least 120 days between prescriptions with no restarts to the end of the post-index period. The 120-day gap was used to account for the recommended dosing regimen for ustekinumab. Augmentation was defined as the proportion of patients starting a new nontopical psoriasis-related medication in the post-index period that was not used in the pre-index period. Concomitant medications were defined as any psoriasis-related medications (including topicals) that were used in the postindex period regardless of whether they were initiated in the pre-index period or newly initiated in the post-index period.

Cost was defined as the total payment to the provider. Resource utilization and costs (outpatient, inpatient, and pharmacy prescriptions) were measured in non-treatment-regimen failures and treatment-regimen failures during the pre- and post-index periods. Total health care costs were the sum of inpatient, outpatient, and pharmacy costs.

\section{Statistical Analysis}

Patient characteristics and medication use between the treatment-regimen-failure and non-treatment-regimen-failure cohorts were compared using analysis of variance (ANOVA) for continuous variables and chi-square tests for categorical variables without adjustment. Cost differences between the 2 cohorts during the post-index period were compared using the propensity score-adjusted bin bootstrapping (PSBB) method. PSBB was used to minimize the potential bias between the cohorts and address the skewed distribution problems of cost data. The PSBB involves the following steps: (1) the propensity score for each patient was computed using logistic regression with the comparison group and other adjustment as the dependent variable; (2) patients were grouped into 5 strata of equal size based on the propensity score quantiles; (3) within each

\section{FIGURE 1 Patient Selection and Flow}

MarketScan patients who newly initiated a biologic between January 1, 2010, and December 31, 2011

$\mathrm{N}=104,312$

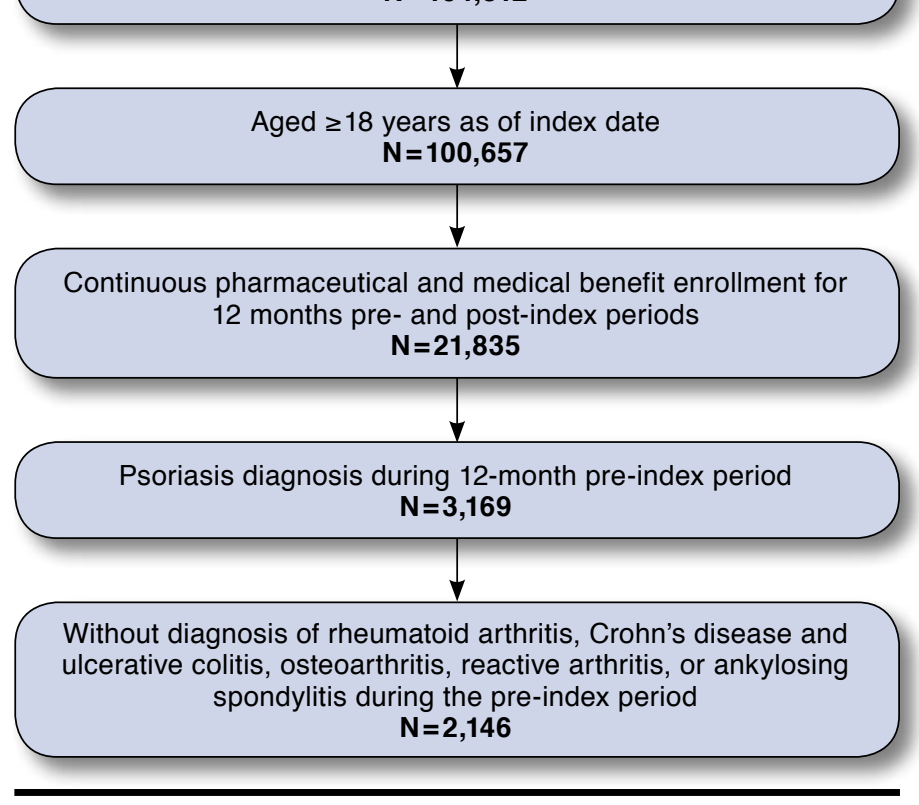

comparison group, 5,000 bootstrapped resamples of fixed sizes were drawn within each stratum, with the total number of samples equaling the total number of patients; and (4) the difference in mean costs between groups was computed for each of the 5,000 replications. Means, medians, standard deviations, and $P$ values were computed from the 5,000 bootstrapped resamples. The variables used for the PSBB adjustment included age, gender, insurance type, Charlson Comorbidity Index, total net cost in pre-index period, comorbidities, medications, and provider type.

\section{Results}

\section{Patient Characteristics}

The final population consisted of 2,146 patients (Figure 1). Patients in this study were a mean age of 45.1 years, with 93.8\% having commercial insurance, $6.2 \%$ having Medicare supplemental insurance, and $71.1 \%$ being treated by a dermatologist (Table 1). A higher proportion of non-treatment-regimen failures than treatment-regimen failures were male $(61.0 \%$ vs. $47.0 \% ; P<0.001)$, whereas a higher proportion of treatmentregimen failures than non-treatment-regimen failures were female $(53 \%$ vs. $39 \%$; $P<0.001)$. Patients who experienced treatment-regimen failure had higher incidences of comorbid cerebrovascular disease ( $2.5 \%$ vs. $1.2 \%$ ), myocardial infarction (1.1\% vs. $0.4 \%$ ), hypertension ( $26.9 \%$ vs. $23.2 \%$ ), chronic pulmonary disease ( $8.4 \%$ vs. $5.4 \%$ ), depression ( $5.6 \%$ vs. $3.0 \%$ ), 


\begin{tabular}{|c|c|c|c|c|c|c|c|}
\hline \multirow{2}{*}{$\begin{array}{l}\text { Patient Characteristic } \\
\text { Demographics (at index) }\end{array}$} & \multicolumn{2}{|c|}{$\begin{array}{c}\text { Total } \\
\mathrm{N}=2,146\end{array}$} & \multicolumn{2}{|c|}{$\begin{array}{c}\text { Non-Treatment- } \\
\text { Regimen Failures } \\
\mathrm{n}=1,255\end{array}$} & \multicolumn{2}{|c|}{$\begin{array}{c}\text { Treatment- } \\
\text { Regimen Failures } \\
\mathbf{n}=891\end{array}$} & \multirow[t]{2}{*}{$\begin{array}{c}\text { Difference } \\
P \text { Value }\end{array}$} \\
\hline & & & & & & & \\
\hline Age at index & & & & & & & 0.350 \\
\hline Mean (SD) & 45.1 & $(13.21)$ & 44.9 & $(12.93)$ & 45.5 & $(13.60)$ & - \\
\hline Gender, n (\%) & & & & & & & $<0.001$ \\
\hline Male & 1,185 & $(55.2)$ & 766 & $(61.0)$ & 419 & $(47.0)$ & - \\
\hline Female & 961 & $(44.8)$ & 489 & $(39.0)$ & 472 & $(53.0)$ & - \\
\hline Primary payer, $\mathbf{n}(\%)$ & & & & & & & 0.061 \\
\hline Commercial & 2,012 & $(93.8)$ & 1,187 & $(94.6)$ & 825 & $(92.6)$ & - \\
\hline Medicare & 134 & $(6.2)$ & 68 & $(5.4)$ & 66 & $(7.4)$ & - \\
\hline \multicolumn{8}{|l|}{ Clinical characteristics (pre-index) } \\
\hline \multicolumn{8}{|l|}{ Comorbidities, n (\%)b } \\
\hline Anxiety & 123 & $(5.7)$ & 61 & $(4.9)$ & 62 & $(7.0)$ & 0.039 \\
\hline Cerebrovascular disease & 37 & $(1.7)$ & 15 & $(1.2)$ & 22 & $(2.5)$ & 0.026 \\
\hline Chronic pulmonary disease & 143 & $(6.7)$ & 68 & (5.4) & 75 & $(8.4)$ & 0.006 \\
\hline Congestive heart failure & 19 & $(0.9)$ & 13 & $(1.0)$ & 6 & $(0.7)$ & 0.377 \\
\hline Coronary atherosclerosis & 86 & $(4.0)$ & 47 & $(3.7)$ & 39 & $(4.4)$ & 0.462 \\
\hline Depression & 88 & $(4.1)$ & 38 & (3.0) & 50 & (5.6) & 0.003 \\
\hline Diabetes & 266 & $(12.4)$ & 156 & $(12.4)$ & 110 & $(12.3)$ & 0.953 \\
\hline Dyslipidemia & 571 & $(26.6)$ & 322 & $(25.7)$ & 249 & $(27.9)$ & 0.237 \\
\hline Hypertension & 531 & $(24.7)$ & 291 & $(23.2)$ & 240 & $(26.9)$ & 0.047 \\
\hline Obesity & 88 & $(4.1)$ & 51 & $(4.1)$ & 37 & $(4.2)$ & 0.919 \\
\hline Mild liver disease & 69 & $(3.2)$ & 45 & (3.6) & 24 & $(2.7)$ & 0.248 \\
\hline Moderate or severe liver disease & 3 & $(0.1)$ & 2 & $(0.2)$ & 1 & $(0.1)$ & 0.773 \\
\hline Myocardial infarction & 15 & $(0.7)$ & 5 & $(0.4)$ & 10 & $(1.1)$ & 0.047 \\
\hline Psoriatic arthritis & 277 & $(12.9)$ & 156 & $(12.4)$ & 121 & $(13.6)$ & 0.434 \\
\hline Renal disease & 28 & $(1.3)$ & 17 & $(1.4)$ & 11 & $(1.2)$ & 0.809 \\
\hline TIA/stroke & 32 & $(1.5)$ & 14 & $(1.1)$ & 18 & $(2.0)$ & 0.088 \\
\hline Unstable angina & 8 & $(0.4)$ & 3 & $(0.2)$ & 5 & $(0.6)$ & 0.228 \\
\hline Charlson Comorbidity Index & & & & & & & 0.180 \\
\hline Mean (SD) & 0.4 & $(0.86)$ & 0.3 & $(0.83)$ & 0.4 & $(0.89)$ & - \\
\hline \multicolumn{8}{|l|}{ Medications, n (\%) } \\
\hline Topicals & 1,758 & $(81.9)$ & 1,024 & $(81.6)$ & 734 & $(82.4)$ & 0.641 \\
\hline Methotrexate & 518 & $(24.1)$ & 295 & $(23.5)$ & 223 & $(25.0)$ & 0.417 \\
\hline Cyclosporine & 65 & $(3.0)$ & 39 & $(3.1)$ & 26 & $(2.9)$ & 0.801 \\
\hline Acitretin & 198 & $(9.2)$ & 108 & $(8.6)$ & 90 & $(10.1)$ & 0.238 \\
\hline Methoxsalen & 10 & $(0.5)$ & 5 & $(0.4)$ & 5 & $(0.6)$ & 0.585 \\
\hline Phototherapy & 269 & $(12.5)$ & 157 & $(12.5)$ & 112 & $(12.6)$ & 0.967 \\
\hline Provider specialty, n (\%) & & & & & & & 0.354 \\
\hline Primary care, internal medicine, general practice & 252 & $(11.7)$ & 144 & $(11.5)$ & 108 & $(12.1)$ & - \\
\hline Dermatologist & 1,525 & $(71.1)$ & 906 & $(72.2)$ & 619 & $(69.5)$ & - \\
\hline Rheumatologist & 81 & $(3.8)$ & 39 & $(3.1)$ & 42 & $(4.7)$ & - \\
\hline Other & 221 & $(10.3)$ & 128 & $(10.2)$ & 93 & $(10.4)$ & - \\
\hline Missing & 67 & $(3.1)$ & 38 & $(3.0)$ & 29 & $(3.3)$ & - \\
\hline \multicolumn{8}{|l|}{ Concomitant medication use (post-index) } \\
\hline \multicolumn{8}{|l|}{ Medication use, n (\%) } \\
\hline Topicals & 1,330 & $(62.0)$ & 733 & $(58.4)$ & 597 & $(67.0)$ & $<0.001$ \\
\hline Methotrexate & 272 & $(12.7)$ & 92 & $(7.3)$ & 180 & $(20.2)$ & $<0.001$ \\
\hline Cyclosporine & 40 & $(1.9)$ & 12 & $(1.0)$ & 28 & $(3.1)$ & $<0.001$ \\
\hline Acitretin & 68 & $(3.2)$ & 12 & $(1.0)$ & 56 & $(6.3)$ & $<0.001$ \\
\hline Concomitant phototherapy & 127 & $(5.9)$ & 67 & $(5.3)$ & 60 & $(6.7)$ & 0.177 \\
\hline
\end{tabular}

aP value is from analysis of variance for continuous variables and chi-square test for categorical variables.

bSee Appendix for ICD-9-CM codes (available in online article).

ICD-9-CM = International Classification of Diseases, Ninth Revision, Clinical Modification; SD=standard deviation; TIA = transient ischemic attack. 


\section{FIGURE 2 Patterns Defining Treatment-Regimen} Failures

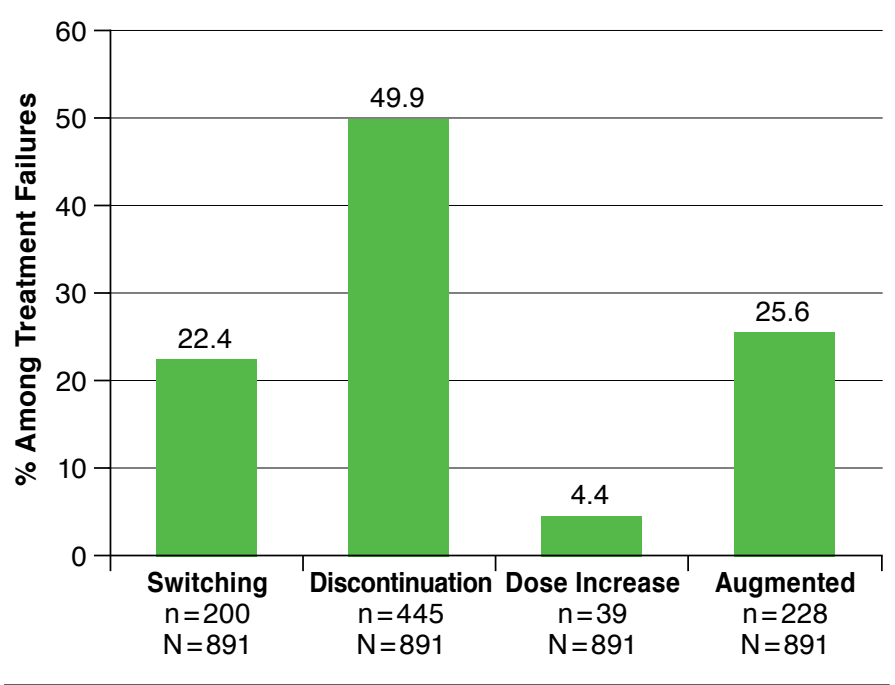

Note: Percentages do not add to $100 \%$ because some patients were included in more than 1 category.

and anxiety (7.0\% vs. $4.9 \%)$ than did non-treatment-regimen failures in the pre-index period.

\section{Patterns of Biologic Therapies}

Overall, $41.5 \%$ of patients were defined as treatment-regimen failures. Among treatment-regimen failures, $22.4 \%$ switched biologic agents (Figure 2). The mean time to switch was 173.0 days (data not shown). The mean length of therapy was 185.2 days (data not shown) among treatment-regimen failures, with $49.9 \%$ of treatment-regimen failures discontinuing therapy. Of 891 treatment-regimen-failure patients, 228 (25.6\%) augmented their therapy with a new nontopical therapy and 39 (4.4\%) had a dose increase.

During the post-index period, fewer non-treatment-regimen failures than treatment-regimen failures used concomitant topicals $(58.4 \%$ vs. $67.0 \% ; P<0.001)$, methotrexate $(7.3 \%$ vs. $20.2 \% ; P<0.001)$, and cyclosporine $(1.0 \%$ vs. $3.1 \% ; P<0.001)$. There was no difference in concomitant phototherapy usage (5.3\% vs. $6.7 \% ; P=0.177$; Table 1 ).

\section{All-Cause Health Care Resource Utilization and Costs}

Non-treatment-regimen failures had, on average, fewer outpatient office visits during both the pre-index period (16.2 vs. 17.9; $P=0.013)$ and post-index period (13.4 vs. $17.2 ; P<0.001)$ than treatment-regimen failures (Table 2). Mean outpatient costs were lower among non-treatment-regimen failures than treatment-regimen failures during both the pre- and post-index periods. Likewise, non-treatment-regimen failures had fewer mean inpatient admissions than treatment-regimen failures during the pre- $(0.2$ vs. $0.3 ; P=0.050)$ and post-index periods (0.3 vs. $0.6 ; P=0.012)$. For pharmacy costs, no significant differences were observed during the pre-index period between non-treatment-regimen failures and treatment-regimen failures $(\$ 2,580$ vs. $\$ 2,508 ; P=0.651)$. However, non-treatment-regimen failures had higher costs during the post-index period $(\$ 25,641$ vs. $\$ 19,398 ; P<0.001)$. Mean total health care costs were lower in non-treatment-regimen failures than in treatment-regimen failures during the pre-index period ( $\$ 6,637$ vs. $\$ 8,024$; $P=0.002$ ) but were higher in non-treatment-regimen failures during the post-index period ( $\$ 30,759$ vs. $\$ 28,012 ; P=0.002)$.

\section{Psoriasis-Related Health Care Resource Utilization and Costs}

On average, non-treatment-regimen failures and treatmentregimen failures had the same number of psoriasis-related outpatient office visits ( 7.7 vs. $7.9 ; P=0.783$ ) during the preindex period, but non-treatment-regimen failures had fewer psoriasis-related outpatient office visits ( 5.0 vs. $5.7 ; P=0.036)$ during the post-index period (Table 3). Non-treatment-regimen failures had lower mean outpatient costs than treatment-regimen failures during the post-index period. A numerically lower proportion of non-treatment-regimen failures than treatmentregimen failures had psoriasis-related inpatient admissions during the pre- $(0.2 \%$ vs. $1.2 \% ; P=0.002)$ and post-index periods $(0.9 \%$ vs. $1.6 \% ; P=0.139)$, but this difference was only significant during the pre-index period. Mean psoriasis-related pharmacy costs were the same in non-treatment-regimen failures and in treatment-regimen failures during the pre-index period ( $\$ 7$ vs. $\$ 4 ; P<0.627$ ) but were higher in non-treatmentregimen failures during the post-index period $(\$ 23,801$ vs. $\$ 17,000 ; P<0.001)$. Likewise, psoriasis-related total health care costs were higher in non-reatment-regimen failures than in treatment-regimen failures ( $\$ 25,286$ vs. $\$ 19,625 ; P<0.001$ ) during the post-index period.

\section{Discussion}

The purpose of this retrospective observational cohort study was to describe characteristics and health care utilization and costs in psoriasis patients who had treatment patterns suggestive of treatment-regimen failure with their first biologic compared with non-treatment-regimen-failure patients. In our study, $41.5 \%$ of patients were considered treatment-regimen failures with an average length of therapy of 185.2 days. Of note, a higher proportion of females than males were treatment-regimen failures, and there were higher incidences of some comorbidities among treatment-regimen failures in the pre-index period.

The proportion of treatment-regimen failures in our cohort is consistent with a retrospective cross-sectional study reported by Levin et al. (2014) that analyzed the clinical practice of 2 dermatologists in the U.S. between January 2008 and January $2012 .{ }^{26}$ This study reported that $48 \%$ of patients failed biologic 


\begin{tabular}{|c|c|c|c|c|c|c|}
\hline & \multicolumn{3}{|c|}{ Pre-index Period } & \multicolumn{3}{|c|}{ Post-index Period } \\
\hline & $\begin{array}{c}\text { Non-Treatment- } \\
\text { Regimen } \\
\text { Failures } \\
\mathrm{n}=1,255 \\
\end{array}$ & $\begin{array}{c}\text { Treatment- } \\
\text { Regimen } \\
\text { Failures } \\
\mathbf{n}=891\end{array}$ & $\begin{array}{c}\text { Difference } \\
P \text { Value }^{\mathrm{a}}\end{array}$ & \begin{tabular}{|c|}
$\begin{array}{c}\text { Non-Treatment- } \\
\text { Regimen } \\
\text { Failures } \\
\mathrm{n}=1,255\end{array}$ \\
\end{tabular} & $\begin{array}{c}\text { Treatment- } \\
\text { Regimen } \\
\text { Failures } \\
\mathrm{n}=891 \\
\end{array}$ & $\begin{array}{c}\text { Difference } \\
P \text { Value }\end{array}$ \\
\hline \multicolumn{7}{|l|}{ Outpatient } \\
\hline Patients with outpatient physician visit, n (\%) & $1,254 \quad(99.9)$ & $891 \quad(100.0)$ & 0.399 & $1,250 \quad(99.6)$ & $879 \quad(98.7)$ & 0.015 \\
\hline Outpatient visits (all), mean (SD) & $16.2 \quad(16.1)$ & $17.9 \quad(16.2)$ & 0.013 & $13.4 \quad(12.3)$ & $17.2 \quad(15.0)$ & $<0.001$ \\
\hline Outpatient costs, US \$ & - & - & 0.002 & - & - & $<0.001$ \\
\hline Mean (SD) & $3,549(6,298)$ & $4,470 \quad(7,387)$ & - & $4,026 \quad(8,126)$ & $6,926(14,535)$ & - \\
\hline Median & 1,682 & 2,121 & - & 1,473 & 2,435 & - \\
\hline \multicolumn{7}{|l|}{ Inpatient } \\
\hline Patients with inpatient admission, $\mathrm{n}(\%)$ & $44 \quad(3.5)$ & $(5.2)$ & 0.059 & $(4.9)$ & $(7.4)$ & 0.017 \\
\hline Inpatient admissions, mean (SD) & $0.2 \quad(1.1)$ & $(1.5)$ & 0.050 & $(2.1)$ & $(2.7)$ & 0.012 \\
\hline Inpatient costs, US \$ & - & - & 0.024 & - & - & 0.301 \\
\hline Mean (SD) & $507(3,694)$ & $1,046 \quad(7,198)$ & - & $1,092(13,856)$ & $1,688 \quad(8,588)$ & - \\
\hline Median & 0 & 0 & - & 0 & 0 & - \\
\hline \multicolumn{7}{|l|}{ Pharmacy, U.S. \$ } \\
\hline Pharmacy costs & - & - & 0.651 & - & - & $<0.001$ \\
\hline Mean (SD) & $2,580(3,757)$ & $2,508 \quad(3,550)$ & - & $25,641(11,712)$ & $19,398(13,291)$ & - \\
\hline Median & 1,389 & 1,388 & - & 25,070 & 17,405 & - \\
\hline Total health care costs, U.S. \$ & - & - & 0.002 & - & - & 0.002 \\
\hline Mean (SD) & $6,637(8,908)$ & $8,024(11,576)$ & - & $30,759(19,866)$ & $28,012(21,583)$ & - \\
\hline Median & 3,938 & 4,583 & - & 27,943 & 24,494 & - \\
\hline \multicolumn{7}{|c|}{$\begin{array}{l}{ }^{a} \text { Costs during pre-index period were compared using analysis of variance. } \\
b \text { Costs during post-index period were analyzed using propensity score bin bootstrapping adjusted for age, gender, insurance type, Charlson Comorbidity Index, total net cos } \\
\text { in prior period, comorbidities, medications, and provider types. } \\
S D=\text { standard deviation; U.S. = United States. }\end{array}$} \\
\hline
\end{tabular}

therapy (as defined by the frequency of discontinuation) in an average of 242 days. Unfortunately, the reasons for failure/discontinuation of biologic treatment in our study are not known. Levin et al. reported that $42 \%$ of patients discontinued biologic therapy due to lack/loss of efficacy, $7.5 \%$ discontinued due to adverse events, and $44 \%$ continued treatment after 4 years. ${ }^{26}$ Other studies reported loss of efficacy, drug no longer needed, and adverse events to be the predominant reasons for biologic discontinuation..$^{27,28}$ An inability to afford the copayment or coinsurance is another potential reason for discontinuation.

Treatment-regimen failures used more concomitant medications than non-treatment-regimen failures during the postindex period. Other than the nontopical concomitant medication used to define treatment failure (methotrexate, cyclosporine, etc.), it is notable that concomitant topical use was also higher in the treatment-regimen-failure group in the post-index period. The use of these medications appeared to decline in both groups from the pre- to post-index periods, which suggests that biologic treatment may result in a reduction in the use of nonbiologic psoriasis medications in at least some patients; however, in other patients, the use of biologics only may be inadequate.
During the pre-index period, mean total all-cause health care costs were lower in non-treatment-regimen failures than in treatment-regimen failures, whereas there was no difference in total psoriasis-related health care costs. Mean outpatient costs were lower in non-treatment-regimen failures than in treatment-regimen failures, which is consistent with there being a lower incidence of some comorbidities among nontreatment-regimen failures.

During the post-index period, treatment-regimen failures had lower all-cause health care costs and psoriasis-related health care costs, most of which were pharmacy-related. Because $49.9 \%$ of treatment-regimen failures discontinued biologic therapy during the post-index period, it is not unexpected that pharmacy-related, and by extension, total health care costs would be reduced. However, this seems to be partially offset by higher outpatient costs among treatment-regimen failures during the post-index period. It should be noted that treatmentregimen failures had higher all-cause outpatient costs during the pre-index period as well, perhaps because they had more comorbidities.

Failing initial treatment with biologics may reduce patient satisfaction and result in the unwillingness to try alternative biologics. This could result in greater resource utilization 


\begin{tabular}{|c|c|c|c|c|c|c|}
\hline & \multicolumn{3}{|c|}{ Pre-index Period } & \multicolumn{3}{|c|}{ Post-index Period } \\
\hline & $\begin{array}{c}\text { Non-Treatment- } \\
\text { Regimen } \\
\text { Failures } \\
n=1,255\end{array}$ & $\begin{array}{c}\text { Treatment- } \\
\text { Regimen } \\
\text { Failures } \\
\mathrm{n}=891\end{array}$ & $\begin{array}{l}\text { Difference } \\
P \text { Value }^{\mathrm{a}}\end{array}$ & \begin{tabular}{|c} 
Non-Treatment- \\
Regimen \\
Failures \\
n=1,255
\end{tabular} & $\begin{array}{c}\text { Treatment- } \\
\text { Regimen } \\
\text { Failures } \\
\mathbf{n}=891\end{array}$ & $\begin{array}{c}\text { Difference } \\
P \text { Value }^{b}\end{array}$ \\
\hline \multicolumn{7}{|l|}{ Outpatient } \\
\hline Patients with outpatient physician visit, n (\%) & $1,253 \quad(99.8)$ & $889 \quad(99.8)$ & 0.730 & $1,198 \quad(95.5)$ & $(89.9)$ & $<0.001$ \\
\hline Outpatient visits, mean (SD) & $7.7 \quad(12.6)$ & $7.9 \quad(12.4)$ & 0.783 & $(7.0)$ & $(7.5)$ & 0.036 \\
\hline Outpatient costs, US \$ & - & - & 0.313 & - & - & 0.026 \\
\hline Mean (SD) & $1,126(4,286)$ & $1,315(4,237)$ & - & $1,456 \quad(5,444)$ & $2,524(10,822)$ & - \\
\hline Median & 392 & 402 & - & 294 & 317 & - \\
\hline \multicolumn{7}{|l|}{ Inpatient } \\
\hline Patients with inpatient admission, $\mathrm{n}(\%)$ & $2 \quad(0.2)$ & $11 \quad(1.2)$ & 0.002 & $(0.9)$ & $(1.6)$ & 0.139 \\
\hline Inpatient admissions, mean (SD) & $0.0 \quad(0.1)$ & $0.0 \quad(0.4)$ & 0.013 & $(0.2)$ & $(0.4)$ & 0.062 \\
\hline Inpatient costs, US \$ & - & - & 0.041 & - & - & 0.107 \\
\hline Mean (SD) & $11 \quad(275)$ & $83(1,210)$ & - & $(437)$ & $101 \quad(1,330)$ & - \\
\hline Median & 0.0 & 0.0 & - & 0.0 & 0.0 & - \\
\hline \multicolumn{7}{|l|}{ Pharmacy } \\
\hline Pharmacy costs, U.S. \$ & - & - & 0.627 & - & - & $<0.001$ \\
\hline Mean (SD) & $7 \quad(140)$ & $4 \quad(115)$ & - & $23,801(10,801)$ & $17,000(12,539)$ & - \\
\hline Median & 0 & 0 & - & 23,679 & 14,656 & - \\
\hline Total health care costs, U.S. \$ & - & - & 0.174 & - & - & $<0.001$ \\
\hline Mean (SD) & $1,144 \quad(4,294)$ & $1,402(4,388)$ & - & $25,286(10,294)$ & $19,625(15,394)$ & - \\
\hline Median & 394 & 404 & - & 24,372 & 17,521 & - \\
\hline \multicolumn{7}{|c|}{$\begin{array}{l}{ }^{a} \text { Costs during pre-index period were compared using analysis of variance. } \\
{ }^{b} \text { Costs during post-index period were analyzed using propensity score bin bootstrapping adjusted for age, gender, insurance type, Charlson Comorbidity Index, total net cos } \\
\text { in prior period, comorbidities, medications, and provider types. } \\
S D=\text { standard deviation; U.S. = United States. }\end{array}$} \\
\hline
\end{tabular}

and costs for the payer. Understanding the characteristics of patients who may be more likely to fail treatment and the potential consequences of that failure would be important information for clinicians when treating their patients and for payers as they make decisions about potential cost-containment efforts (e.g., step edits).

\section{Limitations}

Because only patients with employee-based health insurance or Medicare supplemental insurance were included, patients in this cohort may not have been representative of all psoriasis patients. Data were limited to those that are commonly reported in administrative health care claims, so the possibility of miscoding, errors, and omissions exists, and details regarding the patients' treatment and clinical picture were limited. Another limitation is that it is possible that the 12-month follow-up period was too short to completely capture treatment patterns. Also, the lack of patient randomization may have led to between-group systematic and outcome differences because of unavoidable imbalances between groups.

In addition, a limitation lies in the definition of "non-treatment-regimen failure" and "treatment-regimen failure." Given that this was a retrospective administrative claims analysis, clinical measures were not available to determine whether or not patients did in fact fail treatment. There was no information on the reasons for changes in treatment. It is possible that patients may have switched or discontinued their biologic for reasons unrelated to clinical efficacy, such as formulary changes or an inability to pay for medications. Dose increases or augmentation may not be a result of treatment-regimen failure but rather just part of usual physician prescribing practice. Treatment-regimen failure in this study was defined using treatment patterns similar to that used by Feldman et al. ${ }^{17}$ Although both studies define treatment-related failures by treatment patterns, there were some differences. Feldman et al. used the terminology "treatment failure," which was defined as switching, augmentation with a nontopical agent, discontinuation after uptitration, or discontinuation after hospitalization. ${ }^{17}$ In this study, "treatment-regimen failure" was defined as switching, augmentation with a nontopical medication, discontinuation, or an increase in dose. The differences in definitions are due to the drugs used in the respective studies. The Feldman study evaluated conventional systematic agents, ${ }^{17}$ whereas this study evaluated biologics. It would be uncommon for patients to be hospitalized for psoriasis-related symptoms, and hospitalization related to adverse events associated with 


\section{Patient Characteristics, Health Care Resource Utilization, and Costs Associated with Treatment-Regimen Failure with Biologics in the Treatment of Psoriasis}

biologic use is rare; thus, our definition did not include discontinuation after hospitalization. Similarly, given the costs of biologics, the decision to uptitrate in and of itself is most likely suggestive of a lack of response or loss of response with biologics, so that was used as part of our definition, whereas uptitration with systemic therapies may be more common, and, thus, discontinuation after uptitration may have been more appropriate for the analysis done by Feldman.

\section{Conclusions}

In this study, there were significant differences found in demographic and clinical characteristics and health care-related resource utilization and costs among non-treatment-regimen failures and treatment-regimen failures. Understanding these differences may provide important insights to clinicians and payers in the treatment of psoriasis.

\section{Authors}

SHONDA A. FOSTER, MS, PharmD, is Principal Research Scientist; BAOJIN ZHU, PhD, is Senior Research Scientist; JIAYING GUO, MS, is Associate Consultant Statistician; and ENKELEIDA NIKAI, MSc, EMMEA, is Health Outcomes Researcher, Eli Lilly and Company, Indianapolis, Indiana. CLEMENT OJEH, PhD, is Clinical Research Scientist; WILLIAM MALATESTINIC, PharmD, MBA, is Clinical Research Scientist; and ORIN GOLDBLUM, MD, is Medical Fellow, Lilly USA, Indianapolis, Indiana. LORI J. KORNBERG, PhD, is Senior Medical Writer, INC Research, Raleigh, North Carolina, and JASHIN J. WU, MD, FAAD, is Director of Dermatology Research, Kaiser Permanente Los Angeles Medical Center, Los Angeles, California.

AUTHOR CORRESPONDENCE: Shonda A. Foster, MS, PharmD, Principal Research Scientist, Eli Lilly and Company, Lilly Corporate Center, Indianapolis, IN 46285. Tel.: 317.655.3426;

E-mail:foster_shonda_a@lilly.com.

\section{REFERENCES}

1. Griffiths CE, Barker JN. Pathogenesis and clinical features of psoriasis Lancet. 2007;370(9583);263-71.

2. Nash AS, McAteer H, Schofield J, Penzer R, Gilbert AK. Psoriasis today: experiences of healthcare and impact on quality of life in a major UK cohort. Prim Health Care Res Dev. 2015;16(4):415-23.

3. Fried RG, Friedman S, Paradis C, et al. Trivial or terrible? The psychosocial impact of psoriasis. Int J Dermatol. 1995;34(2):101-05.

4. Sommer DM, Jenisch S, Suchan M, Christophers E, Weichenthal M. Increased prevalence of the metabolic syndrome in patients with moderate to severe psoriasis. Arch Dermatol Res. 2006;298(7):321-28.

5. Edson-Heredia E, Zhu B, Lefevre C, et al. Prevalence and incidence rates of cardiovascular, autoimmune, and other diseases in patients with psoriatic or psoriatic arthritis: a retrospective study using Clinical Practice Research Datalink. J Eur Acad Dermatol Venereol. 2015;29(5):955-63.

6. Famenini S, Sako EY, Wu JJ. Effect of treating psoriasis on cardiovascular co-morbidities: focus on TNF inhibitors. Am J Clin Dermatol. 2014;15(1):45-50.

7. Nguyen T, Wu JJ. Relationship between tumor necrosis factor-alpha inhibitors and cardiovascular disease in psoriasis: a review. Perm J. 2014;18(1):49-54.

8. Wu JJ, Choi YM, Bebchuk JD. Risk of myocardial infarction in psoriasis patients: a retrospective cohort study. J Dermatolog Treat. 2015;26(3):230-34.

9. Wu JJ, Nguyen TU, Poon KY, Herrinton LJ. The association of psoriasis with autoimmune diseases. J Am Acad Dermatol. 2012;67(5):924-30.

10. Belge K, Brück J, Ghoreschi K. Advances in treating psoriasis. F1000Prime Rep. 2014;6:4.

11. Menter A, Gottlieb A, Feldman SR, et al. Guidelines of care for the management of psoriasis and psoriatic arthritis: section 1. Overview of psoriasis and guidelines of care for the treatment of psoriasis with biologics. J Am Acad Dermatol. 2008;58(5):826-50

12. Menter A, Korman NJ, Elmets CA, et al. Guidelines of care for the management of psoriasis and psoriatic arthritis: section 6. Guidelines of care for the treatment of psoriasis and psoriatic arthritis: case-based presentations and evidence-based conclusions. J Am Acad Dermatol. 2011;65(1):137-74.

13. Hsu S, Papp KA, Lebwohl MG, et al.; National Psoriasis Foundation Medical Board. Consensus guidelines for the management of plaque psoriasis. Arch Dermatol. 2012;148(1):95-102.

14. Nast A, Jacobs A, Rosumeck S, et al. Efficacy and safety of systemic longterm treatments for moderate-to-severe psoriasis: a systemic review and meta-analysis. J Invest Dermatol. 2015;135(11):2641-48.

15. Wang J, Wang YM, Ahn HY. Biological products for the treatment of psoriasis: therapeutic targets, pharmacodynamics and disease-drug-drug interaction implications. AAPS J. 2014;16(5):938-47.

16. Mease PJ. Inhibition of interleukin-17, interleukin-23 and the TH17 cell pathway in the treatment of psoriatic arthritis and psoriasis. Curr Opin Rheumatol. 2015;27(2):127-33.

17. Feldman SR, Evans C, Russell MW. Systemic treatment for moderate to severe psoriasis: estimates of failure rates and direct medical costs in a north-eastern US managed care plan. J Dermatolog Treat. 2005;16(1):37-42.

18. Anderson KL, Feldman SR. Reasons for treatment changes in patients with moderate to severe psoriasis. J Cutan Med Surg. 2015;19(4):361-66.

19. Feldman SR, Zhao Y, Navaratnam P, Friedman HS, Lu J, Tran MH. Patterns of medication utilization and costs associated with the use of etanercept, adalimumab, and ustekinumab in the management of moderate-tosevere psoriasis. J Manag Care Spec Pharm. 2015;21(3):201-09. Available at: http://www.jmcp.org/doi/abs/10.18553/jmcp.2015.21.3.201.

20. Humira [package insert]. AbbVie Inc. January 2013. Available at: http:// www.rxabbvie.com/pdf/humira.pdf. Accessed December 26, 2015.

21. Enbrel [package insert]. Amgen, September 2013. Available at: pi.amgen. com/united_states/enbrel/derm/enbrel_pi.pdf. Accessed December 26, 2015. 
Patient Characteristics, Health Care Resource Utilization, and Costs Associated

with Treatment-Regimen Failure with Biologics in the Treatment of Psoriasis

22. Remicade [package insert]. Janssen Biotech Inc. November 2013. Available at: http://www.remicade.com/shared/product/remicade/prescribing-information.pdf. Accessed December 26, 2015.

23. Stelara [package insert]. Janssen Biotech Inc. May 2013. Available at: http://www.stelarainfo.com/pdf/PrescribingInformation.pdf. Accessed December 26, 2015.

24. Chastek B, Watson C, Fox K, Gandra S. Dose escalation of TNF-blocker therapy among patients with psoriasis in a large managed care plan. J Am Acad Dermatol. 2012;66(4):AB190.

25. Bonafede M, Watson C, Fox K, Gandra S. Dose escalation of TNFblockers therapy among US managed care patients with psoriasis. J Am Acad Dermatol. 2012;66(4):AB190.
26. Levin AA, Gottlieb AB, Au SC. A comparison of psoriasis drug failure rates and reasons for discontinuation in biologics vs. conventional systemic therapies. J Drugs Dermatol. 2014;13(7):848-53.

27. Gniadecki R, Kragballe K, Dam TN, Skov L. Comparison of drug survival rates for adalimumab, etanercept and infliximab in patients with psoriasis vulgaris. Br J Dermatol. 2011;164(5):1091-96.

28. Khalid JM, Fox KM, Globe G, Maguire A, Chau D. Treatment patterns and therapy effectiveness in psoriasis patients initiating biologic therapy in England. J Dermatolog Treat. 2014;25(1):67-72. 
Patient Characteristics, Health Care Resource Utilization, and Costs Associated with Treatment-Regimen Failure with Biologics in the Treatment of Psoriasis

\section{APPENDIX ICD-9-CM Codes Used for Comorbidities}

\begin{tabular}{l|l}
\hline Comorbidity & \multicolumn{1}{c}{ ICD-9-CM Code } \\
\hline Anxiety & $300 . x$ \\
\hline Cerebrovascular disease & $362.34,430 . x-438 . x$ \\
\hline Congestive heart failure & $398.91,402.01,402.11,402.91,404.01,404.03,404.11,404.13,404.91,404.93,425.4-425.9,428 . x$ \\
\hline Coronary atherosclerosis & $414 . x$ \\
\hline Chronic pulmonary disease & $416.8,416.9,490 . x-505 . x, 506.4,508.1,508.8$ \\
\hline Depression & $311 . x, 296.2 x, 296.3 x, 300.4 x$ \\
\hline Diabetes & $250.0-250.3,250.8,250.9,250.4-250.7$ \\
\hline Dyslipidemia & $272.0-272.4,272.9$ \\
\hline Hypertension & $401 . x, 405 . x, 642.1 x$ \\
\hline Myocardial infarction & $410 . x, 412 . x$ \\
\hline Mild liver disease & $070.22,070.23,070.32,070.33,070.44,070.54,070.6,070.9,570 . x, 571 . x, 573.3,573.4,573.8,573.9, V 42.7$ \\
\hline Moderate or severe liver disease & $456.0-456.2,572.2-572.8$ \\
\hline Obesity & $278.00,278.01,278.02,278.03$ \\
\hline Psoriatic arthritis & 696.0 \\
\hline Renal disease & $403.01,403.11,403.91,404.02,404.03,404.12,404.13,404.92,404.93,582 . x, 583.0-583.7,585 . x, 586 . x, 588.0$, \\
\hline Transient ischemic attack/stroke & $433 . x x, 434 . x x, 436,435.9$ \\
\hline Unstable angina & 411.1 \\
\hline ICD-9-CM=International Classification of Diseases, Ninth Revision, Clinical Modification.
\end{tabular}

